\title{
Impact estimation on COVID-19 infections following school reopening in September 2020 in Italy
}

\author{
Livio Fenga ${ }^{1, *}$ and Massimo Galli² \\ ${ }^{1}$ Italian National Institute of Statistics, Italy \\ ${ }^{2}$ Dipartimento di Scienze Biomediche e Cliniche “L. Sacco”, Università degli Studi di \\ Milano, Milano, Italy \\ 2Malattie Infettive III Divisione, ASST FBF-Sacco, Milano, Italy \\ *Corresponding author: Livio Fenga, fenga@istat.it
}

\section{(About 3100 words)}

\begin{abstract}
Background Since its outbreak, CoViD-19 (formally known as 2019-nCoV) has been triggering many questions among public authorities, social organisms and school officials, as to when students shouldbe allowed to return to school. Such a decision is critical and must take into account, other than its beneficial effects, also those associated with an increased exposition of the students to the virus, which, as a result, might spread at a faster rate. To date, in Italy, a few studies have rigorously investigated the correlation between school reopening and number of people tested positive to CoViD19. Therefore, this paper aims to provide an assessment of such an impact as well as to illustrate the methodology followed.
\end{abstract}

Methods Official daily data on the cumulative number of people tested positive to CoViD-19 -in conjunction with external information accounting for the different points in time schools reopenedin the various Italian regions - have been employed to build a stochastic model of the type Seasonal Autoregressive Moving Average embodying external information.

Results There was a statistically significant increase in the number of positive cases in all the Italian regions related to schools reopening. Such an increase occurred, in average, about 18.9 days after the schools have been reopened. Schools reopening have been significantly contributed to the diffusion of thepandemic, with an overall estimated impact of about 228,724 positive cases.

Conclusions The results suggest the need for strict control of all in-school activities. This could be done by using, to a variable extent, all the non-pharmaceutical interventions available, such as limited access to school spaces, no overlapping practices between different sports in the same space, universal masking, bubble-size classroom. However, in many cases, such measures might not be a viable option, at least in the short run, nor be reasonably applicable. Therefore, whenever the established safety criteria could not be met, school buildings should remain closed.

Keywords CoViD-19 pandemic; intervention analysis; S-ARIMA-REG models; schools reopening; time series analysis.

\section{Key Messages}

- Due to CoViD-19 pandemic, physical school attendance is at the center of an intense political andsocial debates;

- schools reopening decision should be based on reliable and well maintained data-sets;

- in the lack of quality data, it is advisable to $u^{1}$ se a portion of them, to reduce uncertainty. 
medRxiv preprint doi: https://doi.org/10.1101/2021.06.11.21258733; this version posted June 18, 2021. The copyright holder for this preprint (which was not certified by peer review) is the author/funder, who has granted medRxiv a license to display the preprint in perpetuity.

\section{Introduction}

Especially during epidemics, morbidity and mortality due to secondary bacterial infections can be substantially increased when specific occasions of congregation e.g. physical school attendance, eating in bars and restaurants, attending sporting events - are permitted by public authorities. In such a scenario, potentially dangerous relaxations of some of the countermeasures - purposely taken to contain the spread of the virus - are unfortunately un- avoidable. This is the case of CoViD-19 pandemic, which, among others, has presented unprecedented challenges to the Italian education system, which led to the decision of closing most of the schools between March and June 2020. Such a decision triggered many protests with some of them, as re- ported by all the major national media, resulting in clashes and other social disorders as a consequence of violent and anti-social behaviors. The crisis is still ongoing and this is a delicate matter, given its potential ability to jeopardize the social and democratic fabric of a country ${ }^{12}$. With the school closed, potential educational risks have been highlighted by many experts (e.g. psychologists, professional educators, school officials). In more details, it is noted that hardly ever do students of any age group can fulfill their educational needs in remote learning modes the same way they do under in-person set-ups. In addition, remote learning can have adverse effects on young people in terms of their future social abilities ${ }^{3}$, promote inequalities and reduce the effectiveness of interventions against the risks of suicidality ${ }^{4}$. From a broader perspective, keeping the school open has generally a positive impact on parents' working life, beyond educating children. In fact, families are relieved from all the duties generally fulfilled by schools, e.g. a safe environment, provision of meals, inschool health services. On September 2020, after a vigorous public debate, a controversial decision to reopen the schools was finally taken by the Italian government. This paper focuses on the impact generated by such a determination on the diffusion of CoViD19. The analysis has been carried out at regional level, using official data, as detailed in Section 4. Given the scarcity of school-specific information, populationwide time series - related to the cumulative number of people tested positives (henceforth positive cases or simply positives), stratified at a regional level - have been used. The statistical procedure adopted is based on a stochastic model of the type S-ARIMAREG (short for Seasonal Auto Regressive Integrated Moving Average with external REGressor), which is designed to model exogenous information, that is, in our case, the different dates on which schools reopened (according to the rules established by the regional public authorities). As it will showed, this model proved to be effective in adequately capturing the effect of school reopening on the dynamical behavior of the time series of the cumulative number of positives.

\section{Literature review}

The effects of learn-at-home strategies in flattening the CoViD-19 pandemic curve, have been studied worldwide from various points of view and using different 
medRxiv preprint doi: https://doi.org/10.1101/2021.06.11.21258733; this version posted June 18, 2021. The copyright holder for this preprint (which was not certified by peer review) is the author/funder, who has granted medRxiv a license to display the preprint in perpetuity. It is made available under a CC-BY-NC 4.0 International license.

approaches. A comprehensive, systematic review and meta-analysis of 2178 articles, carried out in 5 , draws (at least) two important conclusions: the lower risks of contracting the infection associated to young people and the overall poor quality of a big chunk of the studies considered. The latter is a particularly striking message as it might be intended as a caveat on some of the results today available in literature. In this regard, a better insight on many of them can be gained by means of the results of a mass seroepidemiological screening, performed in a zone of Italy characterized by unrestricted viral circulation (Castiglione d'Adda), presented in ${ }^{6}$. With that said, there are published and non peer-reviewed articles claiming the limited or even the absence of a significant direct correlation between physical attendance in schools and spread of the virus. In general, such a conclusion is grounded on the fact that children have lower susceptibility to CoViD-19 compared with adults ${ }^{7}$. In this regard, a conservative approach should be followed by taking into consideration that an apparent lower incidence in children might be induced by facts such as reduced exposure and methodological issues, including lower testing ${ }^{8}$. In addition to that, it has to be said that hardly ever do children show obvious symptoms and that school settings often envision small classes and extensive hygiene measures. In a research study focusing on school activities in Italy ${ }^{9}$, it is outlined how the spread of the virus among students occur outside the school buildings, e.g. as a consequence of insufficient transportation or unauthorized social gatherings. However, it seems to be unclear whether such a conclusion is adequately supported by reliable data sources. Intra-class transmission has been found to be a rare event also in a preliminary study ${ }^{10}$ whereas in ${ }^{11}$ no evidence of association between schools and CoViD-19 second wave have been found in Italy. While the former study seems to lack a thorough explanation of the method applied, in the latter the authors explain the two-fold approach followed: a cross sectional and prospective cohort study. However, part of their research questions have been supported on a data sample of limited size, e.g. the Veneto region or one of its province (Verona). In addition, it is not entirely clear how the cross-correlation functions have been estimated (e.g. it might be advisable to use prewhitening techniques $^{12}$ in order to draw more informative conclusions). A prospective, cross-sectional study ${ }^{13}$ - carried out in England based on official data concluded that only "very few cases" of CoViD-19 are attributable to schools opening. In more details, a child has been detected as the potential source of infection in only $29 \%$ of child cases and $17 \%$ of staff cases. Other results for England, reported in ${ }^{14}$, indicate not significant transmission rates in primary schools, before the new CoViD-19 variants started spreading. The impact of school closure in Ontario, Canada, has been assessed in ${ }^{15}$ : the results obtained indicate that school closure had a limited impact on the attack rates. If, on one hand, these studies can be reassuring and have positive effects on the general mood, on the other hand - being based on the assumption of a comparatively small proportion of CoViD-19 cases in children - there is a substantial risk of making wrong inferences on the CoViD-19's transmission capabilities among children in school places. Consistently, many articles warn about the dangers associated with schools reopening: in an 
medRxiv preprint doi: https://doi.org/10.1101/2021.06.11.21258733; this version posted June 18, 2021. The copyright holder for this preprint (which was not certified by peer review) is the author/funder, who has granted medRxiv a license to display the preprint in perpetuity.

It is made available under a CC-BY-NC 4.0 International license .

extensive study ${ }^{16}$ a significant correlation between school closures and the reduction of the reproduction number $R_{t}$ has been found for different time windows and across many countries. A study ${ }^{17}$ carried out in Israel found that, compared with the closing period, the proportion of infected children increased from $19.8 \%$ to $40.9 \%$. In the same direction goes the excellent work ${ }^{18}$, where a clear patio-temporal correlation between school and (delayed) increase in the overall contagion has been showed shown for Italy. The Italian case has been also thoroughly examined within a Bayesian framework in ${ }^{19}$. In their work, the authors found in 15 out of 21 Italian regions - after an average delay of 16.6 days - a change in the rate of growth of the cumulative number of positive cases. Finally, the association between statewide school closure and COVID-19 incidence and mortality has been considered for the US in $^{20}$. The authors found a significant relation between the reduction in both number of positive cases and mortality rate and school closures, even though other concurrent non pharmaceutical actions might have played a role in such a reduction.

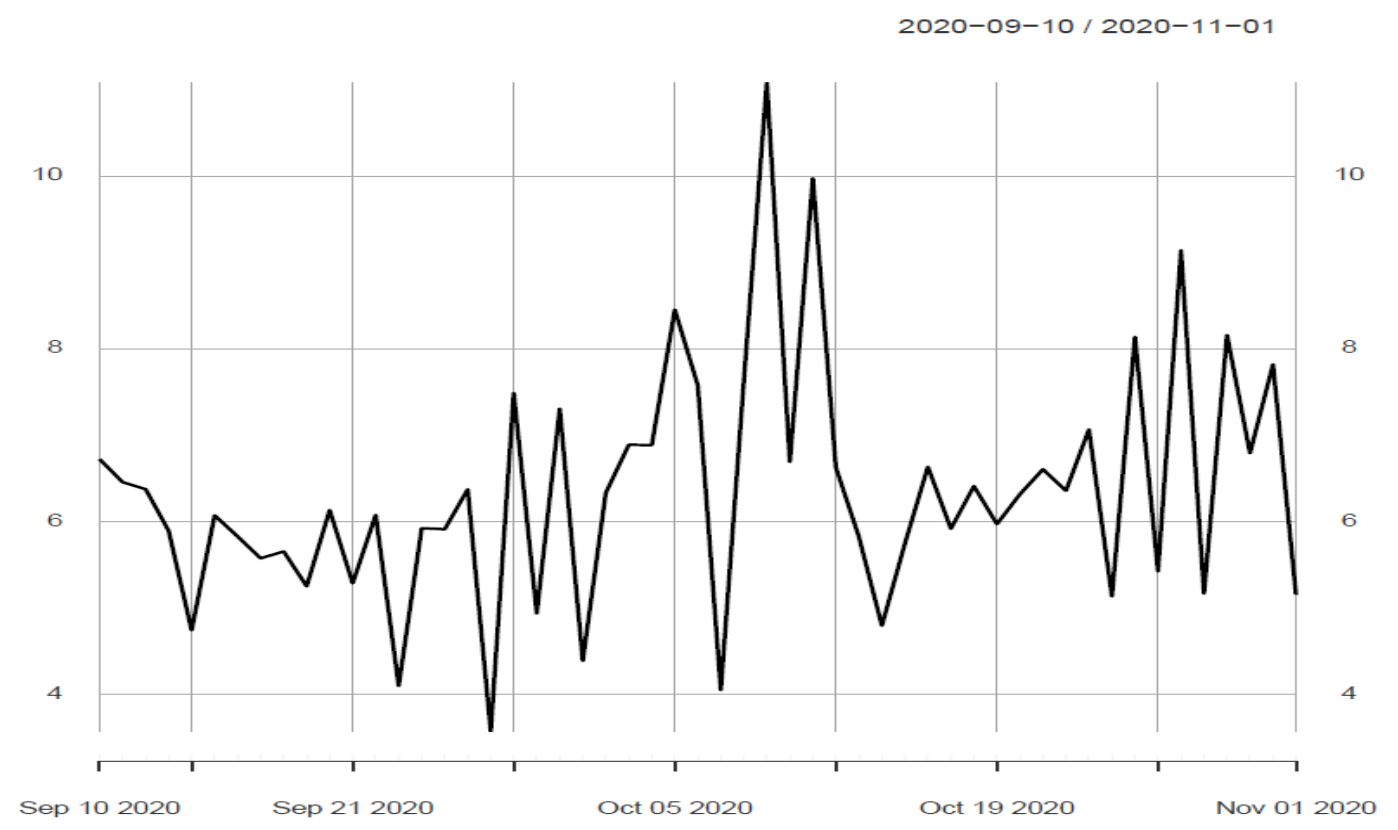

Fig. 1 Outcome sequence of the $t-$ test associated to the parameter $\beta$ (i.e. the estimated additional number of positive cases) for the Trento region. The highest value $t^{*}$ is reached on October 10, 2020 
medRxiv preprint doi: https://doi.org/10.1101/2021.06.11.21258733; this version posted June 18, 2021. The copyright holder for this preprint (which was not certified by peer review) is the author/funder, who has granted medRxiv a license to display the preprint in perpetuity.

It is made available under a CC-BY-NC 4.0 International license.

\begin{tabular}{clcccc}
$\begin{array}{c}\text { Geogr. } \\
\text { distrib. }\end{array}$ & \multicolumn{1}{c}{$\begin{array}{c}\text { Region } \\
\text { name }\end{array}$} & $\begin{array}{c}\text { Schools } \\
\text { starting dates }\end{array}$ & $\begin{array}{c}\text { Days to } \\
\text { max impact }\end{array}$ & $\begin{array}{c}\text { School-related } \\
\text { positives }\end{array}$ & $\begin{array}{c}\text { Statistical } \\
\text { significance }\end{array}$ \\
\hline \multirow{5}{*}{ North } & $09 / 14$ & 27 & 16448 & 3.9 \\
& Piedmont & $09 / 14$ & 11 & 57 & 5.9 \\
& Valle d'Aosta & $09 / 14$ & 30 & 44780 & 2.8 \\
& Lombardy & $09 / 07$ & 27 & 800 & 6.6 \\
& Bolzano & $09 / 03$ & 37 & 256 & 11.1 \\
& Frento & $09 / 14$ & 19 & 3644 & 6.3 \\
& Liguria & $09 / 14$ & 20 & 8504 & 7.8 \\
& Emilia Romagna & $09 / 14$ & 18 & 13697 & 2.6 \\
& Veneto & $09 / 14$ & 18 & 12917 & 6.8 \\
& & & & \\
Center & & & 23584 & 4.0 \\
& Lazio & $09 / 14$ & 21 & 7011 & 6.0 \\
& Marche & $09 / 14$ & 20 & 14846 & 4.1 \\
& Toscana & $09 / 15$ & 20 & 1292 & 3.3 \\
& Umbria & $09 / 14$ & 20 & 1228 & 22.3 \\
& Abruzzo & 12 & & \\
& Basilicata & $09 / 22$ & & 1239 & 1.8 \\
& Calabria & $09 / 24$ & 9 & 271 & 2.9 \\
& Campania & $09 / 24$ & 9 & 37545 & 2.1 \\
South & $09 / 24$ & 8 & 100 & 2.9 \\
& Molise & $09 / 14$ & 22 & 24498 & 1.9 \\
Apulia & $09 / 24$ & 9 & 87883 & 5.8 \\
Sicily & $09 / 21$ & 19 & 4.0
\end{tabular}

Table 1 Impact of schools reopening in terms of positive cases (fifth column) broken down for geographic distribution and Italian regions (first and second columns). School starting dates are reported in the third column whereas the fourth one accounts for the number of days passed between the schools starting dayand the effect in terms of positive cases (encoded in the vector $\left.V_{t+k}\right)$ attributable to schools reopening. The last column 6 stores the greatest $t$ values $\left(t^{\mathbb{Z}}\right)$. See text for details 
medRxiv preprint doi: https://doi.org/10.1101/2021.06.11.21258733; this version posted June 18, 2021. The copyright holder for this preprint (which was not certified by peer review) is the author/funder, who has granted medRxiv a license to display the preprint in perpetuity.

\section{Method}

The mathematical methods generally used for description, prediction and simulation purposes in the case of CoViD19 are those typically used for other epidemic events (e.g. Ebola, Zika, MERS$\mathrm{CoV}$ ). For a review of the most used approaches, the reader is referred to ${ }^{21} 22$ 23. As above mentioned, the results provided in this article are obtained within the framework of the time series analysis. In particular, a stochastic model of the type S-ARIMA-REG has been employed (to the best of the authors' knowledge, this is the first time such a method has been applied to address research questions similar to that investigated in this paper). Time dependent data have been extensively employed in epidemiology24 252627282937 and modeled by a variety of stochastic models, including S-ARIMA. Introduced in 1970 by Box and Jenkins ${ }^{33}$, these type of models have been successfully used in many fields of research, including epidemiology, see e.g. ${ }^{24} 29$ 16. A S-ARIMAREG model takes the form of a time $t$, $t \in \mathbb{Z}^{+}$, indexed difference equation which can be expressed as

$$
\begin{aligned}
& \phi_{p}(B) \Phi_{P}\left(B^{S}\right) \underset{S}{D d}\left(x_{t}-\mu-\sum_{j=1}^{s} \beta_{j} V_{j, t+k}\right. \\
+ & \left.u_{t}\right)+ \\
= & \theta_{0}+\theta_{q}(B) \Theta_{Q}\left(B^{S}\right) \alpha_{t} ; t=1,2, \ldots, T .
\end{aligned}
$$

Denoting with $B, d$, and $D$ the backward shift operator and the non-seasonal and seasonal difference operator, respectively, defining ${ }^{d}=1-B^{d}$ and ${ }^{D}=1-B^{D}$, we have $\phi_{p}(B)=1-\phi_{1} B-$ $\phi_{2} B^{2}-\ldots-\phi_{p} B^{p}, \quad \theta_{q}(B)=1-\theta_{1} B-$ $\theta_{2} B^{2}-\ldots-\theta_{q} B^{p}, \quad \Phi_{P}\left(B^{S}\right)=1-\Phi_{1} B^{S}-$ $\Phi_{2} B^{2 S}-\ldots-\Phi_{P} B^{P S}$, and $\Theta_{Q}\left(B^{S}\right)=1-$ $\Theta_{1} B^{S}-\Theta_{2} B^{2 S}-\ldots-\Theta_{q} B^{Q S}$. Here, $\phi, \theta, \Phi$, $\Theta$, respectively, denote the non-seasonal autoregressive and moving average parameters and the seasonal autoregressive and moving average parameters. Finally, $\alpha_{t}$ is a 0 -mean white noise with finite variance $\sigma^{2}$ whereas the estimation algorithm adopted in this paper is of the type Maximum Likelihood. Exogenous information is captured by the matrix $V_{j, t+k}$, being $k \in \mathbb{Z}^{+}$, weighted by the parameter vector $\beta_{j}$. In our setup, however, the schools reopening date is the only external input - and thus the matrix $V_{j, t+k}$ collapses to a simple $0-1$ dummy vector, denoted by the symbol $V_{t+k}$, weighted by the scalar parameter $\beta_{j}$. In more details, the vector $V_{t+k}$ takes the value 0 before the school opening plus a lag $k$ and 1 afterwords. In such a way, the $\beta$ parameter expresses a steady mean variation - which is known also with the term "level shift" - from the time the dummy variable transitions from the state 0 to 1 onward. The integer $k$ plays a key role in our analysis, as it captures the delay at which the greatest effect on cumulative positives cases is detected. Due to its efficient design, Equation 1 can describe two scenarios: one assuming that the intervention (schools opening) 
medRxiv preprint doi: https://doi.org/10.1101/2021.06.11.21258733; this version posted June 18, 2021. The copyright holder for this preprint (which was not certified by peer review) is the author/funder, who has granted medRxiv a license to display the preprint in perpetuity.

has never happened - and one which "acknowledges" it. The former, also known as a counterfactual or hypothetical scenario, is built by simply subtracting the estimated impact $\beta$ to the series of cumulative positives located from $t_{0}+k$ onward, with $t_{0}$ being the school starting date. In symbols $x_{t}-\beta ; t=t_{0}, t_{0+1}, \ldots, T-1, T$, being $T$ the last observation in the observed sample and $x_{t}$ the variable of interest. Due to the observed systematic reduction of the number of tests administrated during the weekends, a S-ARIMA structure - designed to account for periodic components embedded in the underlying stochastic process - has been chosen over the simpler ARIMA model (where no periodicity is accounted for).

The algorithm employed to generate the results, presented in the next Section 4, iteratively maximizes the explanation capabilities of the vector $V_{t+k}$ (Equation 1) through a grid search approach, performed over a set of reasonable tentative delays $k_{1}, k_{2}, \ldots, k_{K}$. In practice, model (1) is re-estimated $K-k+1$ times (the models have been always checked for both stationary and invertibility conditions ${ }^{2}$ ) and the final SARIMA-REG structure selected using the Minimum Akaike Information Criterion Estimate procedure ${ }^{33} 34$, being the grid search exhaustively examined in the interval $[7 ; 60]$. Recalling $t_{0}$ to be the school starting date, for each region the algorithm extracts the delay $t_{0}+k^{*}$ at which the maximum impact - in terms of positive cases - is generated by the schools opening. Such an assessment, is based on the largest statistical significance, expressed by the value of the $t$-test, associated to the $(K-k+1) \beta$ parameters recursively estimated. In symbols: $\quad\left(k^{*}, \beta^{*}\right)=\max _{k}\left\{\frac{\widehat{\beta}}{\sigma(\widehat{\beta})}\right\} \quad$ under $\frac{\widehat{\beta}}{\sigma(\widehat{\beta})} \geq 1.96$ (i.e. the $95 \%$ confidence interval for which $\beta \neq 0$ ). In practice, for each region the algorithm returns the sequence of $60-7+1=54$ outcomes of the t-test, whose maximum is taken to select the value of $k$, i.e. $k^{*}$, as the day number, following the relaxation of the schools closure $\left(t_{0}\right)$, where the impact of such a measure is maximized. For example, Figure 1 portrays the sequence of $\mathrm{t}$-values (one for each day between day 7 and day 60 after the schools starting dates) related to the Trento region. The peak located on October 9, 2020 indicates that the greatest impact has occurred $k^{*}=37$ days $\left(t^{*}=11.1\right)$ after the schools have been reopened. Once the time delay has been established, the estimated $\beta$ parameter associated to the dummy variable $V_{t+37}$ accounts for the number of positive cases attributable to the event schools opening $\left(t_{0}\right)$ shifted by $k^{*}=37$ days, which in this case is equal to 256 . In practice, the vector $V_{t+k^{*}} ; k^{*}=37$ is simply a sequence of 0 s between February 24 and 0ctober 8 and of 1s from October 9 onward. Being sampled-based, the estimation of the number of positives $\beta^{*}$ generated by (1) has been extrapolated, for each region, to population scale through a suitable inference procedure ${ }^{35} 27$. In practice, the following multiplying factor, i.e.

$$
w * 2^{\frac{\tau}{\delta}}
$$

with

$$
w=\frac{C}{M},
$$

has been built, so that the final number of positives at a population level is given by 
medRxiv preprint doi: https://doi.org/10.1101/2021.06.11.21258733; this version posted June 18, 2021. The copyright holder for this preprint (which was not certified by peer review) is the author/funder, who has granted medRxiv a license to display the preprint in perpetuity. It is made available under a CC-BY-NC 4.0 International license .

$\beta^{*}\left(w * 2^{\frac{\tau}{\delta}}\right)$. Here, $w$ is the ratio between the current positive cases $(C)$ and the number of deaths $(M), \tau$ the Covid-19 average doubling time (i.e. the average span of time needed for the virus to double the cases) and $\delta$ the average time needed for an infected person to die. While $\delta$ has been kept fixed and set to 6.2 $\left(\mathrm{see}^{36}\right)$, the parameter $\tau$ has been empirically estimated for each region, using as a benchmark the number of positives recorded in the first school day and counting the number of days needed for this number to double. The number of deaths $M$ are also available at the same official web address above given.

\section{Results}

The data used in this paper are made available by the Italian Civil Protection Department and publicly accessible, free of charge, at the following web-address: https: //github.com/pcm-dpc (file name: "dpc-covid19-ita-regioni-20210211.csv").

The variable of interest, stored in column 11 and labeled "Totale Positivi" (i.e. cumulative number of positives), consists of 407 daily data points collected at a regional level during the period February $24^{\text {th }} 2020$ - April, $5^{\text {th }}$ 2021. Even though the official number of Italian regions is 20 , one special administrative region (called Trentino Alto Adige) is considered as two separate subregions: Trento and Bolzano. Table 1 shows the results broken down for geographical distribution and each Italian region (respectively listed in the first and second column) in terms of the estimated number of positives cases attributable to schools reopening, reported in column 5. The statistical significance of these estimations is reported in column 6 , whereas column 3 stores the schools starting dates. Finally, column 4 accounts for the number of days passed between the first school day and the day where the $t$-value reaches its maximum value. In almost all the cases saved for Liguria and Veneto where a six days periodicity has been determined the underlying seasonality chosen is always of 7 days. Such a periodic fluctuation in the data should not be associated with any epidemiological reasons being related to the screening procedures, which typically slow down on weekends. The estimated overall impact of schools reopening is quantified in around 227,724 positives whereas the mean time delay (henceforth denoted with the symbol $\mu_{D}$ ) is of about 19 days, with standard deviation (henceforth denoted with the symbol $\sigma_{D}$ ) of around 7.5 days. Such estimates are consistent with what found in literature, see, e.g.. Schools reopening has been estimated to generate the greatest in the following regions: Lombardy, Piedmont (northern regions), Lazio and Tuscany (center regions), Campania and Apulia (southern regions). Those cases account for almost $50 \%$ of the estimated total impact. Lombardy is the most impacted region, with an estimated number of schoolsrelated positives of more than 44,780 cases (delay time $k^{*}=30$ days), whereas Calabria, Trento, Molise and Valle d'Aosta, are under the 300 positives threshold. Basilicata is the only region where the estimated model exhibits a not completely satisfactorily $t$-value $\left(t^{*}=\right.$ 1.8). The reason of that is probably linked to the high degree of roughness showed by the time series in the time window of interest, which might have resulted in a problematic convergence of the estimation algorithm. As for the time delay, for many regions our results are comparable to those reported in. In 
medRxiv preprint doi: https://doi.org/10.1101/2021.06.11.21258733; this version posted June 18, 2021. The copyright holder for this preprint (which was not certified by peer review) is the author/funder, who has granted medRxiv a license to display the preprint in perpetuity. It is made available under a CC-BY-NC 4.0 International license.

average, the values of $k^{*}$ tend to decrease from north $\left(\mu_{D}=23\right.$ and $\left.\sigma_{D}=7.9\right)$ to center $\left(\mu_{D}=20.2\right.$ and $\left.\sigma_{D}=.5\right)$ and south $\left(\mu_{D}=14\right.$ and $\left.\sigma_{D}=6.6\right)$.

\section{Discussion}

The results obtained, clearly indicate the existence of a range of factors explaining the second wave of September in Italy. Our opinion is that those factors should include schools reopening, whose correlation with the rise of the epidemic curve has been statistically proven. These results call for a strict control of all the activities carried out in the school buildings. Such a goal can be achieved by using, to a variable extent, all the non pharmaceutical interventions available, such as limited access to school spaces, no overlapping practices between different sports in the same space, universal masking, bubble-size classroom, extensive hygiene. Reopening schools in a staged fashion - e.g. by year groups or location (e.g. rural or urban) - is thus an option, as proposed in ${ }^{38}$. However, it is a fact that in many cases, such measures might not be a viable option, at least in the short run, nor be reasonably applicable. Therefore, whenever the established safety criteria could not be met, these school buildings should remain closed. Lack of reliable information and intrinsic limitations of the S-ARIMA-REG scheme, prevented us from designing a more complex model, e.g. able to test and discriminate among different triggering factors. With that said, we believe that the methodological approach chosen has one main advantage over the methods based on multiple data sources: we used one single variable (the cumulative positives cases) and one auxiliary information (the schools starting date). As a result of that, the amount of uncertainty surrounding the whole analysis has been drastically reduced. In addition, the theoretical framework chosen makes possible the extraction of useful information including counterfactual scenarios, as mentioned in Section 3- on the dynamical behavior of the diseases and an easier interpretation of the results.

\section{References}

[1] Jane Kenway and Debbie Epstein. The covid-19 conjuncture: rearticulating the school/home/work nexus. International Stud- ies in Sociology of Education, pages 1-26, 2021.

[2] Daisuke Nagakura. A note on how to impose stationarity and invertibility conditions in ARMA model estimation: A review. Avail- able at SSRN 1262156, 2008.

[3] $\mathrm{R}$ Jeffrey Melton and Robert C Sinclair. Culture, covid-19, mask mandates, and reopening economies: Psychological economics, the successes of collectivist countries, and the failures of individualistic countries.

[4] Oren Miron, Kun-Hsing Yu, Rachel Wilf- Miron, Isaac Kohane, and Nadav Davidovitch. Covid-19 infections following physical school reopening. Archives of disease in childhood, 2020.

[5] Wei Xu, Xue Li, Marshall Dozier, Yazhou He, Amir Kirolos, Zhongyu Lang, Catherine Mathews, Nandi Siegfried, Evropi Theodoratou, et al. What is the evidence for transmission of covid-19 by children in schools? a living systematic review. Journal of Global Health, 10(2), 2020. 
medRxiv preprint doi: https://doi.org/10.1101/2021.06.11.21258733; this version posted June 18, 2021. The copyright holder for this preprint (which was not certified by peer review) is the author/funder, who has granted medRxiv a license to display the preprint in perpetuity. It is made available under a CC-BY-NC 4.0 International license .

[6] Gabriele Pagani, Andrea Giacomelli, Federico Conti, Dario Bernacchia, Rossana Rondanin, Andrea Prina, Vittore Scolari, Arianna Rizzo, Martina Beltrami, Camilla Caimi, et al. Prevalence of sars-cov-2 in an area of unrestricted viral circulation: Mass seroepidemiological screening in Castiglione d'Adda, Italy. PloS one, 16(2):e0246513, 2021

[7] Russell M Viner, Oliver T Mytton, Chris Bonell, GJ Melendez-Torres, Joseph Ward, Lee Hudson, Claire Waddington, James Thomas, Simon Russell, Fiona Van Der Klis, et al. Susceptibility to sars-cov-2 infection among children and adolescents compared with adults: a systematic review and meta-analysis. JAMA pediatrics, 175(2):143-156, 2021.

[8] Zoe Hyde. Difference in sars-cov-2 attack rate between children and adults may reflect bias. PMID: 33631791 PMCID: PMC7989594 D0I: 10.1093/cid/ciab183

[9] Giovanni Sebastiani and Giorgio Palù. Covid-19 and school activities in Italy. Multidisciplinary Digital Publishing Institute, 2020.

[10] Danilo Buonsenso, Cristina De Rose, Rosanna Moroni, and Piero Valentini. Sars-cov-2 infections in Italian schools: preliminary findings after one month of association of introducing and lifting nonpharmaceutical interventions with the time-varying reproduction number of sars-cov-2: a modelling study across 131 countries. The Lancet Infectious Diseases, 21(2):193-202, 2021.

[11] Sara Gandini, Maurizio Rainisio, Maria Luisa Iannuzzo, Federica Bellerba, Francesco Cecconi, and Luca Scorrano. A cross-sectional and prospective cohort study of the role of schools in the sarscov-2 second wave in Italy. The Lancet Regional Health-Europe, 5:100092, 2021.

[12] Wilke Hendriks, Hendriek Boshuizen, Arnold Dekkers, Mirjam Knol, Ge A Donker, Arie van der Ende, and Hester Korthals Altes. Temporal crosscorrelation between influenza-like illnesses and invasive pneumococcal disease in the Netherlands. Influenza and other respiratory viruses, 11(2):130-137, 2017.

[13] Sharif A Ismail, Vanessa Saliba, Jamie Lopez Bernal, Mary E Ramsay, and Shamez N Ladhani. Sars-cov-2 infection and transmission in educational settings: a prospective, cross- sectional analysis of infection clusters and out- breaks in England. The Lancet Infectious Dis- eases, 21(3):344-353, 2021.

[14] Shamez N Ladhani, Frances Baawuah, Joanne Beckmann, Ifeanichukwu 0 Okike, Shazaad Ahmad, Joanna Garstang, Andrew J Brent, Bernadette Brent, Jemma Walker, Nick Andrews, et al. Sars-cov-2 infection and trans- mission in primary schools in england in June- December, 2020 (skids): an active, prospective surveillance study. The Lancet Child \& Adolescent Health, 2021.

[15] Elaheh Abdollahi, Margaret HaworthBrockman, Yoav Keynan, Joanne M Langley, and Seyed M Moghadas. Simulating the effect of school closure during covid-19 outbreaks in Ontario, Canada. BMC medicine, 18(1):1-8, 2020.

[16] Steven Riley, Kylie EC Ainslie, Oliver Eales Caroline E Walters, Haowei Wang, Christina J Atchison, Claudio Fronterre, Peter J Diggle, Deborah Ashby, Christl A Donnelly, et al. High prevalence 
medRxiv preprint doi: https://doi.org/10.1101/2021.06.11.21258733; this version posted June 18, 2021. The copyright holder for this preprint (which was not certified by peer review) is the author/funder, who has granted medRxiv a license to display the preprint in perpetuity. It is made available under a CC-BY-NC 4.0 International license.

of sars-cov-2 swab positivity and increasing $\mathrm{r}$ number in England during October 2020: React-1 round 6 interim report. medRxiv, 2020.

[17] Chen Stein-Zamir, Nitza Abramson, Hanna Shoob, Erez Libal, Menachem Bitan, Tanya Cardash, Refael Cayam, and Ian Miskin. A large covid-19 outbreak in a high school 10 days after schools' reopening, Israel, may 2020. Eurosurveillance, 25(29):2001352, 2020.

[18] Davide Tosi and Alessandro Siro Campi. How schools affected covid-19 pandemic in italy: Data analysis for Lombardy region, Campania region, and Emilia region. 2021. Future Internet, 2021, 13.5: 109.

[19] Luca Casini and Marco Roccetti. Reopening Italy's schools in September 2020: A Bayesian estimation of the change in the growth rate of new sarscov- 2 cases. medRxiv, 2021.

[20] Katherine A Auger, Samir S Shah, Troy Richardson, David Hartley, Matthew Hall, Amanda Warniment, Kristen Timmons, Dianna Bosse, Sarah A Ferris, Patrick W Brady, et al. Association between statewide school closure and covid-19 incidence and mortality in the us. Jama, 324(9):859-870, 2020.

[21] Fred Brauer, Carlos Castillo-Chavez, and Zhilan Feng. Mathematical models in epidemiology, volume 32. Springer, 2019.

[22] Andrew B Lawson. Statistical methods in spatial epidemiology. John Wiley \& Sons, 2013.

[23] Amy H Auchincloss, Samson Y Gebreab, Christina Mair, and Ana V Diez Roux. A review of spatial methods in epidemiology, 2000-2010. Annual review of public health, 33:107 - 122, 2012.
[24] James Lopez Bernal, Steven Cummins, and Antonio Gasparrini. Interrupted time series regression for the evaluation of public health interventions: a tutorial. International journal of epidemiology, 46(1):348-355, 2017.

[25] Ramesh Chandra Das. Forecasting incidences of covid-19 using Box-Jenkins method for the period July 12-septembert 11, 2020: A study on highly affected countries. Chaos, Solitons \& Fractals, 140:110248, 2020.

[26] Mohsen Maleki, Mohammad Reza Mahmoudi, Darren Wraith, and Kim-Hung Pho. Time series modelling to forecast the confirmed and recovered cases of covid19. Travel medicine and infectious disease, 37:101742, 2020.

[27] Livio Fenga. Covid-19: an automatic, semiparametric estimation method for the population infected in Italy. PeerJ, 9:e10819, 2021.

[28] Gregory L Watson, Di Xiong, Lu Zhang, Joseph A Zoller, John Shamshoian, Phillip Sundin, Teresa Bufford, Anne W Rimoin, Marc A Suchard, and Christina M Ramirez. Pandemic velocity: Forecasting covid-19 in the us with a machine learning \& Bayesian time series compartmental model. PLOS Computational Biology, 17(3): e1008837, 2021.

[29] Livio Fenga. Forecasting the covid19 diffusion in Italy and the related occupancy of intensive care units. medRxiv, 2020.

[30] Shujuan Li, Wei Cao, Hongyan Ren, Liang Lu, Dafang Zhuang, and Qiyong Liu. Time series analysis of hemorrhagic fever with renal syndrome: A case study in jiaonan county, china. Plos one, 11(10):e0163771, 2016. 
medRxiv preprint doi: https://doi.org/10.1101/2021.06.11.21258733; this version posted June 18, 2021. The copyright holder for this preprint (which was not certified by peer review) is the author/funder, who has granted medRxiv a license to display the preprint in perpetuity.

It is made available under a CC-BY-NC 4.0 International license .

[31] Mahmood Moosazadeh, Narges Khanjani, Mahshid Nasehi, and Abbas Bahrampour. Predicting the incidence of smear positive tuberculosis cases in Iran using time series analysis. Iranian journal of public health, 44(11):1526, 2015.

[32] Ulrich Helfenstein. The use of transfer function models, intervention analysis and related time series methods in epidemiology. International journal of epidemiology, 20(3):808-815, 1991.

[33] George Box, Gwilym M Jenkins, and G Reinsel. Time series analysis: forecasting and control holden-day San Francisco. Time Series Analysis: Forecasting and Control Holden Day1970, 1970.

[33] Hirotugu Akaike. Modern development of statistical methods. In Trends and progress in system identification, pages 169-184. Elsevier, 1981.

[34] Hirotugu Akaike. A Bayesian analysis of the minimum aic procedure. In Selected Papers of Hirotugu Akaike, pages 275280. Springer, 1998.

[35] Thomas Pueyo.Coronavirus: Why you must act now.

https://medium.com/@tomaspueyo/cor onavirus373 act-today-or-people-willdie-f4d3d9cd99ca,2020.

[36] You Li, Harry Campbell, Durga Kulkarni, Al- ice Harpur, Madhurima Nundy, Xin Wang, Harish Nair, Usher Network for COVID, et al. The temporal The temporal association of introducing and lifting non-pharmaceutical interventions with the time-varying reproduction number (R) of SARS-CoV-2: a modelling study across 131 countries. The Lancet Infectious Diseases, 2021, 21.2: 193-202.
[37] Livio Fenga and Mauro Gaspari. Predictive capacity of covid-19 test positivity rate. Sensors, 21(7):2435, 2021.

[38] Russell M Viner, Christopher Bonell, Lesley Drake, Didier Jourdan, Nicolette Davies, Valentina Baltag, John Jerrim, Jenny Proimos, and Ara Darzi. Reopening schools during the covid-19 pandemic: governments must balance the uncertainty and risks of reopening schools against the clear harms associated with prolonged closure. Archives of disease in childhood, 106(2):111-113, 2021 